\title{
The Relationship between Contact Resistance and Contact Force on Au coated Carbon Nanotube surfaces.
}

E. M. Yunus
pgesa@soton.ac.uk
J.W. McBride

J.W.Mcbride@soton.ac.uk
S.M Spearing

S.M.Spearing@soton.ac.uk

.School of Engineering Sciences, University of Southampton SO17 1BJ

\begin{abstract}
Carbon-Nanotube (CNT) coated surfaces are investigated to determine the electrical contact performance under low force conditions. The surfaces under investigation are multi-walled CNTs formed on a Silicon substrate and coated with an Au film. These planar surfaces are mated with a hemispherical Au plated probe mounted in a nano-indentation apparatus. The maximum contact force used is $1 \mathrm{mN}$. The contact resistance of these surfaces is investigated as a function of the applied force and is also studied under repeated loading cycles. The surfaces are compared with a reference Au-Au contact under the same experimental conditions and the results compared to established contact theory. The results show that the multi-walled CNT surface provides a stable contact resistance, but that the performance could be improved further with the application of single-walled CNT coatings. This initial study shows the potential for the application of CNT surfaces as an interface in low force electrical contact applications.
\end{abstract}

Keyword: nano-indentation apparatus, contact resistance, carbon nanotubes, and Au/multi walled carbon nanotubes.

I.

INTRODUCTION.

The paper presents a study of electrical contact surfaces under low force conditions, typically below $1 \mathrm{mN}$. Such condition are relevant to micro-contact applications, for example MEMS relay devices. There are a number of potential materials for such applications and Gold, Palladium or Platinum are commonly used [1]. The disadvantage of such materials are that they are relatively soft and easily wear. Other materials which are of interest for MEMS devices are silicon carbide and diamond. Both have high moduli but a low electrical conductivity. This makes them unsuitable for electrical contact applications. When $\mathrm{SiC}$ film is doped with $\mathrm{NH}_{3}$ the resistivity drops to $1 \times 10^{-4} \Omega \mathrm{m}[2]$ and DLC is doped with ruthenium the resistivity drops to $1 \times 10^{-5} \Omega \mathrm{m}$ [3] but both materials have higher resistivity compared to gold and its alloys (for example Au-6.3\% Pt has a resistivity of $\left.7.17 \times 10^{-8} \Omega \mathrm{m}\right)$ [1].
A carbon nanotube surface (CNT) has potential as a material for MEMS relay applications as a contact material because of its excellent mechanical and electrical properties. In a recent experiment [4], Au contacts with a substrate coated with tangled single walled carbon nanotubes were investigated. The authors concluded that a tangled SWNT film against an $\mathrm{Au}$ coated surface works better than two contacting tangled films.

The following mechanical properties have been determined; CNTs are tested to have a tensile strength of 63 $\mathrm{GPa}$ [5] and compared with high-carbon steel which has a tensile strength of approximately 1.2 GPa. Experiments using an atomic force microscopy were performed to measure the elastic modulus and bending strength of individual structurally isolated multi-wall carbon nanotubes indicated values of $1.26 \mathrm{TPa}$ and $14.2 \mathrm{GPa}$ [6] respectively. Experiments were also conducted on CNTs using nanoindentation apparatus and values were obtained for the bending modulus; $1.24 \mathrm{TPa}$, axial modulus; $1.23 \mathrm{TPa}$ and wall modulus; 5.61 TPa [7]. Another report shows that CNT's have an elastic modulus greater than $1 \mathrm{TPa}$ [8] compared to diamond, which is $1.2 \mathrm{TPa}$.

It is estimated that a $4-10 \mu \mathrm{m}$ long Single Walled Carbon Nanotube (SWNT) with a diameter of $1.2 \mathrm{~nm}$ has a resistivity of $0.88 \times 10^{-8} \Omega \mathrm{m}$ and it is thought to exhibit ballistic electrical conduction. In addition, when a CNT is filled with metal, to form a composite its resistivity falls to $0.35 \times 10^{-8} \Omega \mathrm{m}$ [9]. The mechanical and electrical properties are therefore potentially comparable to diamond and gold respectively, but no experiments have been reported on CNT metal composites for micro-contact applications.

\section{MATERIAL PREPARATION.}

In this study three contact pairs have been investigated; $\mathrm{Au}$ to $\mathrm{Au}, \mathrm{Au}$ to multi walled carbon nano-tubes (MWNT) and $\mathrm{Au}$ to $\mathrm{Au} / \mathrm{MWNT}$ composite. The geometry selected is shown in Fig. 1 with a $2 \mathrm{~mm}$ diameter hemisphere contacting a flat surface. In all cases the hemisphere consists of a stainless steel base, sputter coated with $\mathrm{Au}, 500 \mathrm{~nm}$ thick, with surface roughness $\mathrm{R}_{\mathrm{a}} \approx 400 \mathrm{~nm}$. In experiment 1 , the flat surface is a silicon $(\mathrm{Si})$ substrate $(\sim 5 \mathrm{~mm}$ by $\sim 5 \mathrm{~mm})$, sputter coated with $\mathrm{Au} 500 \mathrm{~nm}$, with a surface roughness $\mathrm{R}_{\mathrm{a}} \approx 30 \mathrm{~nm}$. 
In experiment 2, a "forest" of MWNT is grown on the Si wafer as shown in Fig 2 using thermal CVD. The catalyst used is sputter deposited $\mathrm{Fe}$ and the gaseous carbon source is ethylene. The growth temperature and time is $875^{\circ} \mathrm{C}$ and 5 minutes respectively to produce vertically aligned MWNT of $\sim 50 \mu \mathrm{m}$ in length.

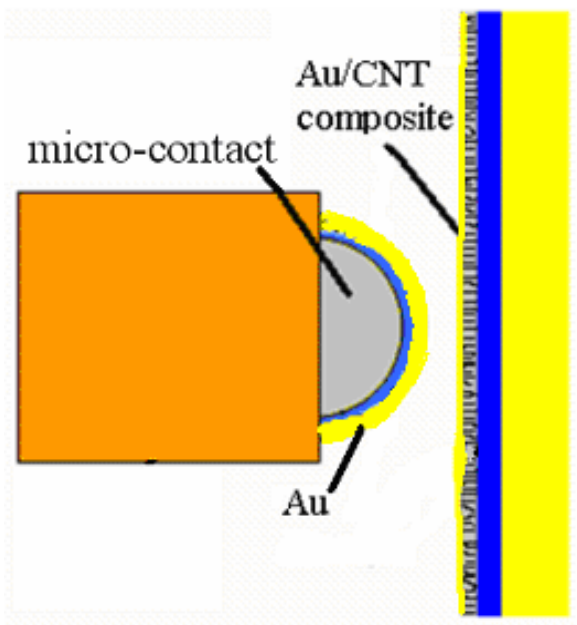

Figure 1: Schematic layout of the Au-Micro-contact and $\mathrm{Au} / \mathrm{CNT}$ composite Substrate.

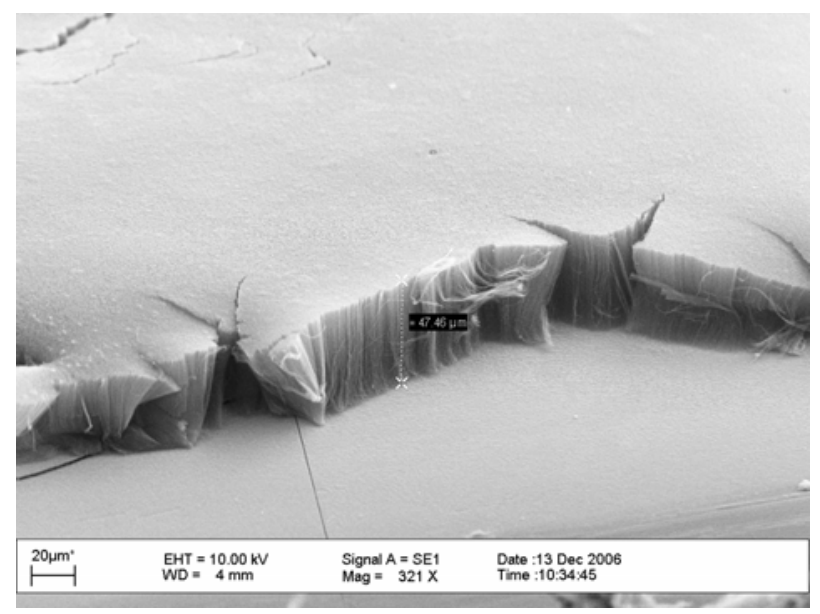

Figure 2: Sample 2, SEM image of a forest of MWNT.

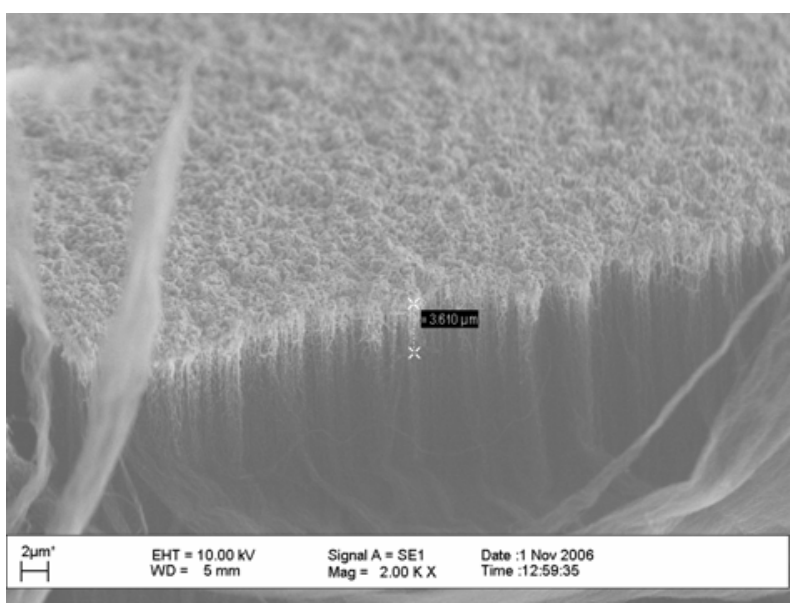

Figure 3: Sample 3, Au coating on MWNT by Sputtering.
Experiment 3 is the same as experiment 2, but with $\mathrm{Au}$ sputtered on the upper surface of the MWNT forest $(50 \mu \mathrm{m}$ in length) to produce $\mathrm{Au} / \mathrm{MWNT}$ composite coatings as shown in Fig 3. It is shown that the Au penetrates the MWNT surface to a depth of 2 to $4 \mu \mathrm{m}$.

\section{EXPERIMENTAL METHOD.}

To achieve the low forces required a modified nanoindentation apparatus [10] is used, by replacing the diamond indenter tip with the hemispherical contact surfaces shown in Fig's 4 and 5. The force and electrical contact resistance (CR) can be measured simultaneously. The force measurement is intrinsic to the apparatus and the CR is measured using the 4wire measurement method as shown Fig 5. The DC current source across the micro-contact and the substrate is set at $1 \mathrm{~mA}$ using a Keithley 580 micro-ohmeter.

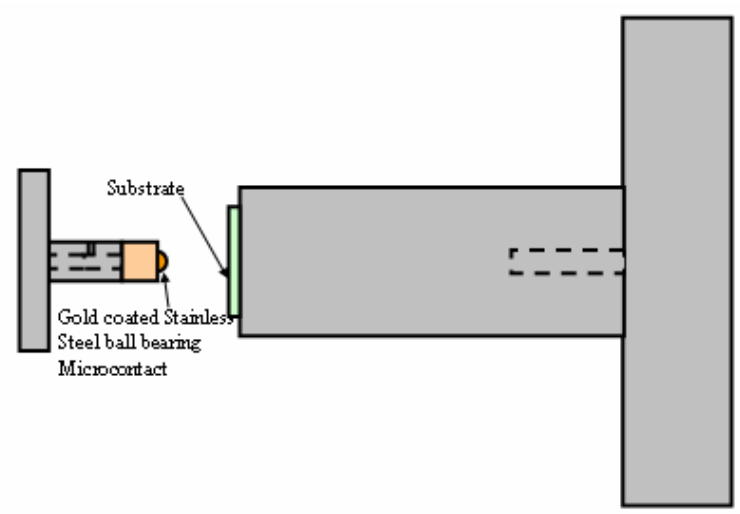

Figure 4: Schematic of Modified Nanoindenter.

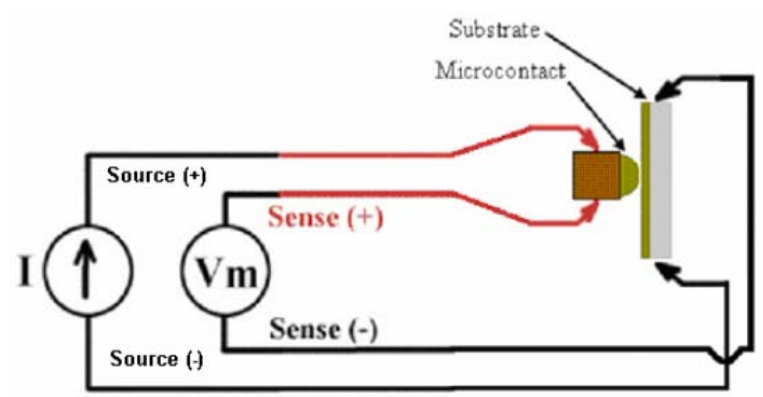

Figure 5: Schematic of contact zone with its electrode and CR measurement.

The experimental apparatus is maintained at a constant temperature of $31^{\circ} \mathrm{C}$. This is to prevent any thermal drift affecting the experiment due to expansion of the apparatus or the specimens. The coated micro-contact and substrate are brought into contact at a controlled loading rate of $0.2 \mathrm{mN} / \mathrm{s}$ until the maximum load of $1 \mathrm{mN}$ is reached. The targeted load will be held for 10 seconds so that an average peak load resistance value can be determined. The electrode contacts are then unloaded at the same rate until they are separated. Fig 6 shows an example of the CR variation over one load cycle. This procedure is repeated in order to detect any cyclic changes in the electrical contact resistance. In this figure, during the unloading period the contacts remain together leading to "sticking". 


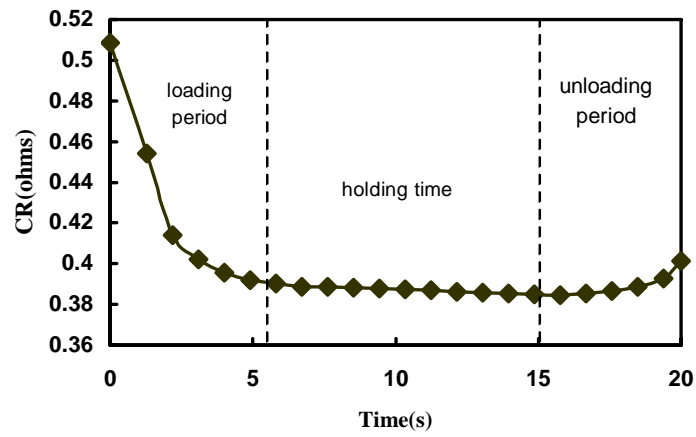

Figure 6: Example of one load cycle for an $\mathrm{Au}-\mathrm{Au}$ contact pair.

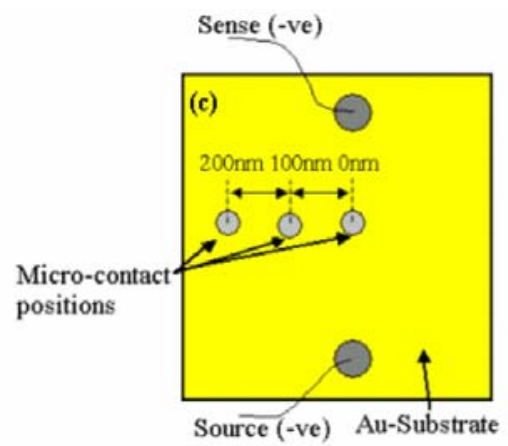

Figure 7: Top view micro-contact positions on the Ausubstrate.

Prior to the experiment two control measures are used. (1) To determine the bulk resistance of the component. By changing the width between the Sense (ve) and Source(-ve) point on the substrate, Fig 7. In addition the micro-contact is moved across at $100 \mathrm{~nm}$ and $200 \mathrm{~nm}$ as shown schematically in Fig 7 . Both tests give the same resistance reading $\sim 0.38 \Omega$. This confirms that the 4-wire measurement method measures the contact resistance and not the bulk resistance. (2) To determine the nature of the film conduction. In this test the contact resistance across the Au micro-contact with the substrate coated by the catalyst only (i.e. no MWNT) is measured and no conduction is detected. This shows that the conduction is only through the MWNT and Au/MWNT coatings.

\section{RESULTS AND DISCUSSION.}

\section{A. Load-contact resistance characteristic for experiment $1(A u-A u)$}

Fig 8 shows the characteristic of the $\mathrm{Au}-\mathrm{Au}$ contact pair up to a maximum load of $1 \mathrm{mN}$. Assuming that the micro-contact deforms plastically the analytical result is plotted on the same graph using the following equation (Holm's analytical model) [11]:

$$
R_{c}=\left(\frac{\rho^{2} \eta \pi H}{4 F}\right)^{\frac{1}{2}}
$$

$$
\begin{aligned}
& \text { Where } \rho=2.24 \times 10^{-8} \Omega \mathrm{m} \text {. } \\
& \qquad H=1.7 \times 10^{9} \mathrm{~N} / \mathrm{m}^{2}, \text { for sputtered Au. [11] }
\end{aligned}
$$

The measured data are higher than the analytical model using the above formula. This is most likely because in the analytical model the contact surfaces are assumed to be clean (assume $\eta=1$ ) but in the experiment there are likely to be surface films and contaminants thus giving a higher contact resistance. In addition to the potential contamination the classical theory represented in (1) is expected to provide significant errors when compared to the experiments conducted here. Firstly the classical model assumes a large solid conduction body, and a diffusion dominated conduction model. Under the conditions with low force and with thin film surfaces the model will need to be modified. This was partially undertaken by Coutu [12], who considered the contact mechanics and the associated contact resistance under the low force conditions typical of MEMS relays, where conduction is likely to dominated by ballistic electron transport. The model proposed by Coutu does not account for the thin film mechanics, or the use of a thin film conduction surface on a CNT substrate where the CNT deformation is expected to dominate the mechanics of the surface interactions.

Using the formula from [12] which is an updated micro-contact resistance model for low force contact developed using Chang's [13] improvement to the Chang, Etsion, and Bogy (CEB) model [14] and Gamma function in Wexler interpolation [15], we can simulate the new microcontact resistance as shown below, using the new microcontact Wexler resistance model for elastic-plastic deformation, [12];

$$
R_{c}^{\prime}=R_{c}\left(\text { ballistic) }+\Gamma(K) R_{c}\right. \text { (diffusive) (eqn. 2) }
$$

Where $R_{c}$ (ballistic) is the contact resistance equation based on ballistic electron transport and elastic-plastic material deformation, $R_{c}$ (diffusive) is the contact resistance equation based on diffusive electron transport and elasticplastic material deformation and $\Gamma(K)$ is the Gamma function.

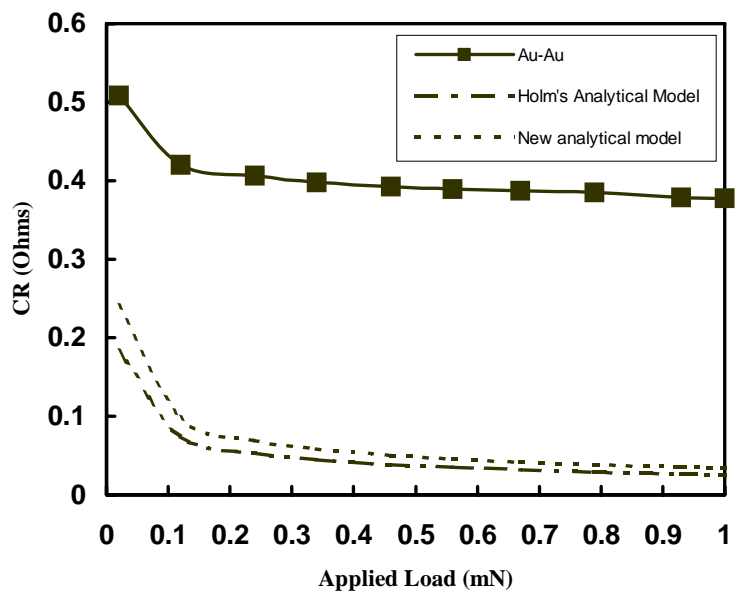

Figure 8: Contact resistance between $\mathrm{Au}-\mathrm{Au}$ contact pair as a function of applied load. 
The new analytical model (eqn.2) gives a predicted contact resistance slightly higher than Holm's contact resistance. In this model; (1) the new microcontact resistance considers elastic-plastic material deformation, (2) it uses a single effective a-spot rather than multiple a-spots, (3) conduction during the microrelay's closure is considered to be a mixture of ballistic and diffusive electron transport and (4) the contact load discontinuity (which exists at the transition from ideal elastic to ideal elastic-plastic behaviour) is accounted for. The new model falls short of the measured values and it is therefore concluded that the existing models for contact resistance are not applicable and further consideration should be given to the influence of thin film conduction.

\section{B.Modified Contact Resistance for Thin-Films}

The theory presented in the previous section is based upon the analysis of bulk materials. There are two important factors not considered.

1. The conduction in a thin film upon a nonconducting surface.

2. The local hardness value, which is expected to differ from the bulk value.

In the case of the former an FEA model of a $500 \mathrm{~nm} \mathrm{Au}$ film, shown in Fig. 9, modelled on the $1 \mathrm{mN}$ contact force with the same values of $H$ and $\rho$ used in Equ. 1, leads to a predicted contact area of $0.56 \mu \mathrm{m}^{2}$ based on $\mathrm{F} / \mathrm{H}$. The model is a simple $2 \mathrm{D}$ axi-symmetric system. This models a 3D system with the current fed through a cylindrical electrode. This generates a predicted constriction resistance of $62 \mathrm{~m} \Omega$, compared to the $26 \mathrm{~m} \Omega$ in Fig. 8 . This is still short of the $0.4 \Omega$ measured, but clearly identifies the importance of thin film conduction.

In the case of the latter, it has been suggested that the local work hardening of the asperities could lead to an increased hardness value [11]. This would further reduce the contact area and increase the constriction resistance.

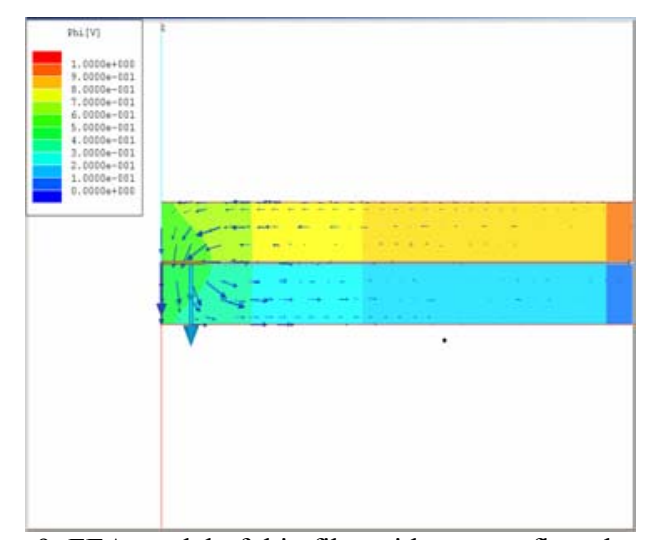

Figure 9: FEA model of thin film with current flow through a $500 \mathrm{~nm}$ Au film with a contact area of $0.58 \mu \mathrm{m}^{2}$.
C. Load-contact resistance characteristic for experiment 2 (Au-MWNT)

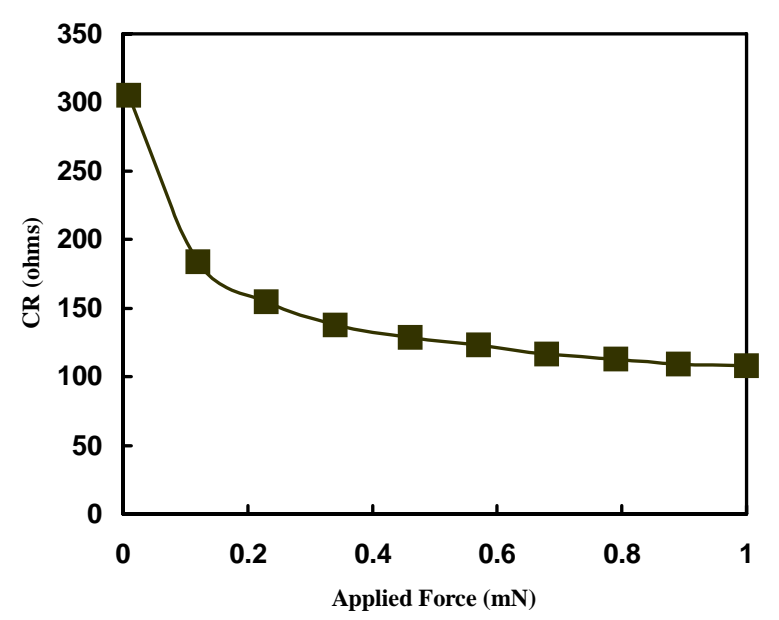

Figure 10: Contact resistance between Au-MWNT contact pair as a function of applied load.

Fig 10 shows the contact resistance against an applied load of the Au-MWNT contact pair. Fig 11 shows a scanned image of a MWNT surface showing asperities and a surface roughness, $\mathrm{R}_{\mathrm{a}} \approx 1.3 \mu \mathrm{m}$. Fig 12 shows a corresponding SEM image of the top surface of a MWNT coated surface.

In this experiment, the dominant factor is expected to be the deflection of the MWNTs rather than plastic indentation. As the applied load is increased, more deflection occurs of the MWNTs closing the air gaps between the vertically aligned MWNTs thus improving the transfer of electrons. Furthermore the MWNTs will conform to the form of the Au micro-contact, increasing the contact area.

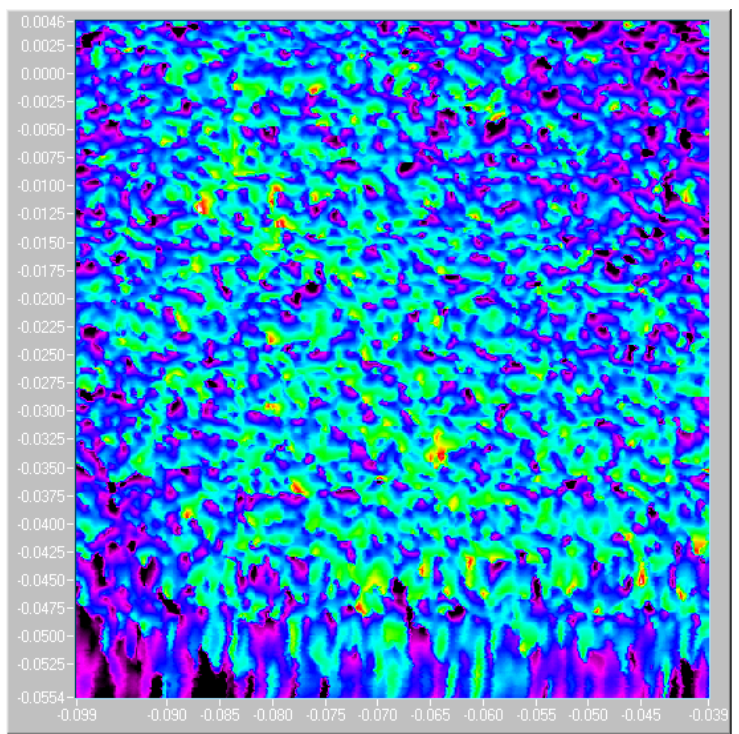

Figure 11: Scanned image of MWNT 301x301 $(60 \mu \mathrm{m} \times 60 \mu \mathrm{m})$ using TaiCaan (Xyris 4000CL). 


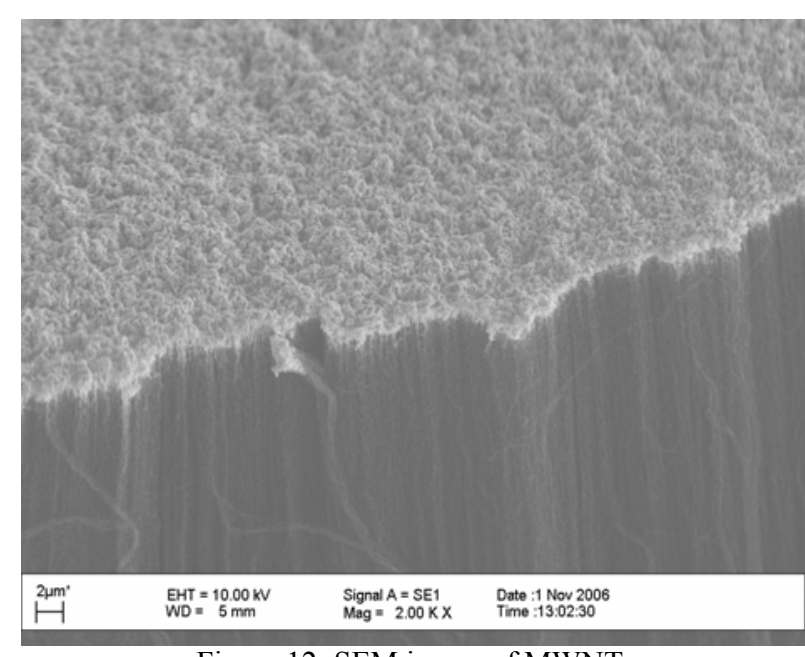

Figure 12: SEM image of MWNT.

\section{Load-contact resistance characteristic for experiment} $3(A u-A u / M W N T)$

A similar trend to that shown in Figs 8 and 10 can be seen with the $\mathrm{Au}-\mathrm{Au} / \mathrm{MWNT}$ contact pair, shown in Fig 13. In this case the contact resistance is much lower than for the Au-MWNT contact pair and higher than Au-Au contact pair (also shown). The Au coating on MWNT makes contact with the Au micro-contact thus leading to a decrease in the contact resistance.

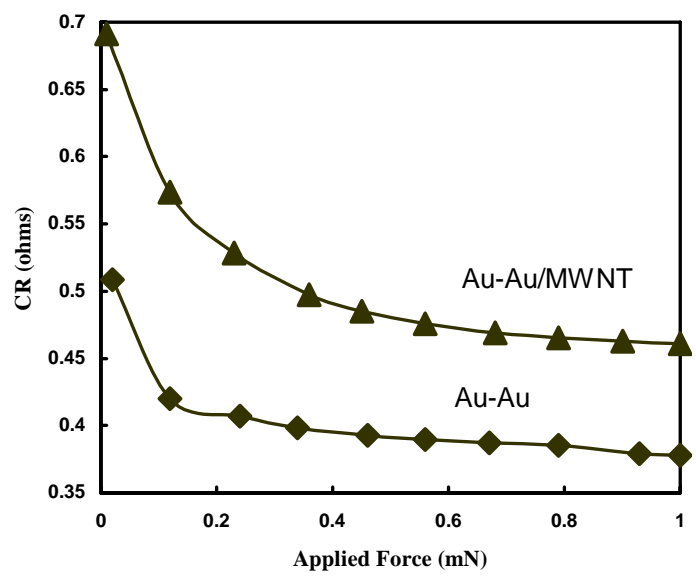

Figure 13: Contact resistance between $\mathrm{Au}-\mathrm{Au}$ and $\mathrm{Au}-$ $\mathrm{Au} / \mathrm{MWNT}$ coating contact pair as a function of applied load.

\section{E. Cyclic loading}

Fig 14 shows the contact resistance of an Au$\mathrm{Au}$ pair over 10 load cycles at a maximum applied load of $1 \mathrm{mN}$. The points include the corresponding standard deviation of the contact resistance measured during the hold period.

A recent experiment [10] using a modified nano-indentation apparatus shows the Au-Pt contact pair degrading and the contact resistance increasing after the $10^{\mathrm{th}}$ cycle. It was proposed that this is due to hot- switched contact arcing. In this experiment no current loading occurs so the contacts are unlikely to degrade by "hotswitching", therefore the increase in contact resistance is solely due to the deterioration of the Au-Au contact pair surfaces. Au is a very soft metal (typically low hardness 1$2 \mathrm{GPa}$ ), has a low melting point, and is susceptible to wear.

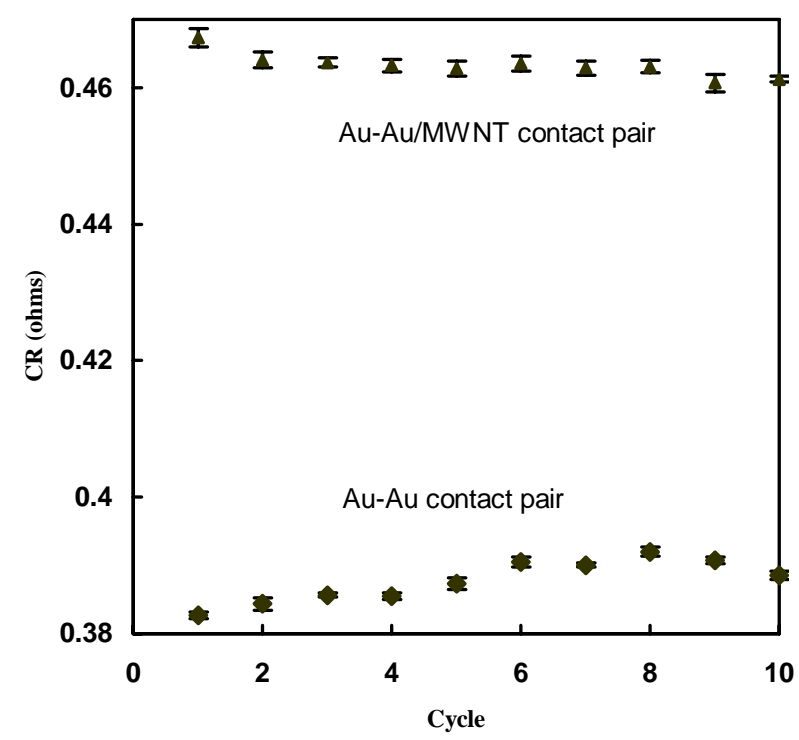

Figure 14: Cyclic contact resistance of $\mathrm{Au}-\mathrm{Au}$ and $\mathrm{Au}-\mathrm{Au} / \mathrm{MWNT}$ contact pair.

Fig 15 shows the contact resistance of Au-MWNT contact pair during cyclic load. The contact resistance of the Au-MWNT contact pair during cyclic load is higher $(\sim 108 \Omega)$ than the Au-Au contact pair $(\sim 0.39 \Omega)$.

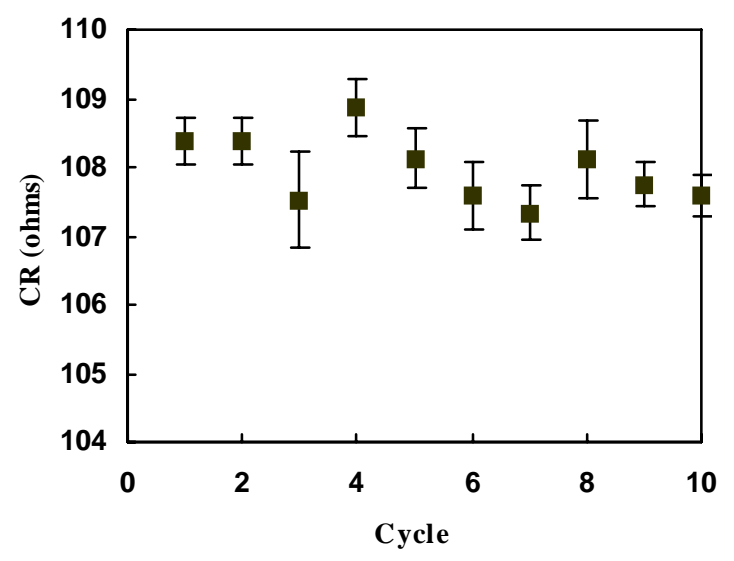

Figure 15: Cyclic contact resistance of an Au-MWNT contact pair.

Fig 14 also shows the contact resistance of an Au$\mathrm{Au} / \mathrm{MWNT}$ contact pair. The contact resistance is similar to the Au-MWNT contact pair (Fig 15) but lower $(\sim 0.46 \Omega)$. The results show stability over the first 10 loading cyles. 


\section{F. Load-Displacement Characteristic of the surfaces}

Fig 16 shows a graph of "load versus displacement" (data extracted from the nano-indentation apparatus). However, before describing them, we first describe the general features of the load-displacement responses we have observed from the experiment. The curve in region 1 shows the loading and the curve in region 3 shows the unloading of the micro-contact. The curve in region 2 shows there is creep, a deformation that occurs over a period of time when a material is subjected to constant stress at constant temperature. Region 4 is the permanent depth deformation after the contact pair separates.

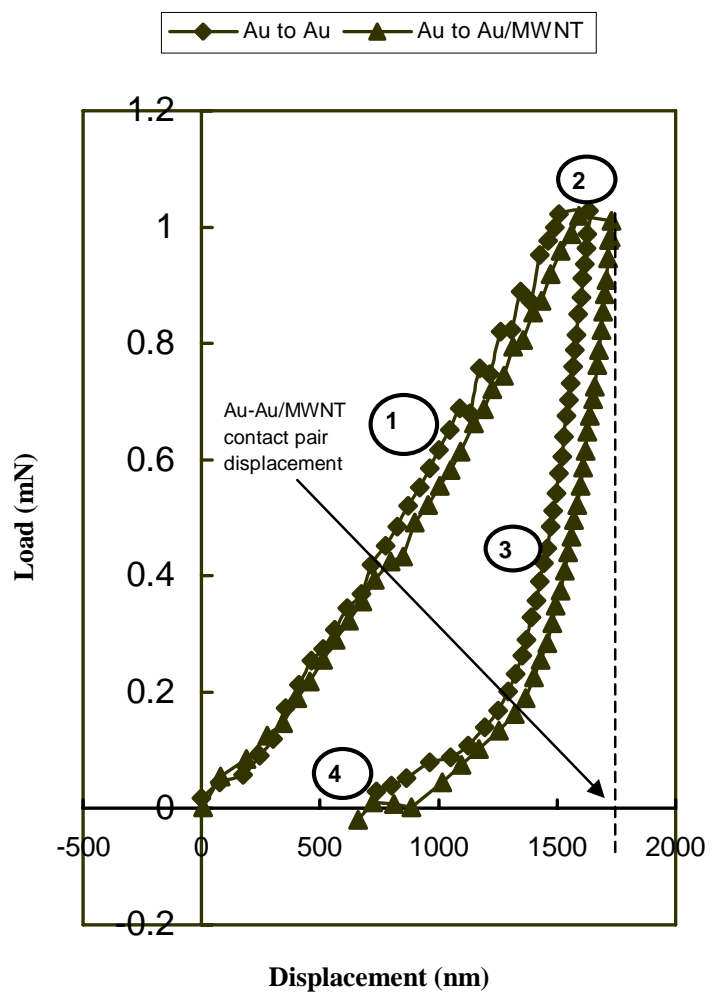

Figure 16: Graph of applied load against depth.

From Fig 16 it can be seen that the displacement of the $\mathrm{Au}-\mathrm{Au} / \mathrm{MWNT}$ contact pair is greater than for the Au-Au contact pair, this will provide a larger conducting surface area. Fig 17 shows the comparison of $\mathrm{Au}-\mathrm{Au} / \mathrm{MWNT}$ with a Au-MWNT contact pair where the Au-Au/MWNT contact pair has a significant permanent indentation (Fig 17, at region ' 5 ') and Au-MWNT contact pair shows much less permanent indentation (Fig 17 at region ' 6 '). This is consistent with the MWNT deforming elastically whereas the $\mathrm{Au}$ undergoes plastic deformation.

Fig 18, shows an SEM image of the Au (ball) contact surface after the load cycles. It shows some damage to the Au surfaces. When an area marked ' $A$ ' was scanned using a non-contact $3 \mathrm{D}$ laser profiler (TaiCaan Xyris 4000CL) many impression or marks on the $\mathrm{Au}$ micro-contact are detected as shown in a $3 \mathrm{D}$ scanned surface in Fig 19 (b), which can be compared to a new surface in Fig 19 (a). These impression or marks are due to the asperities on the MWNT or Au/MWNT. Moreover the surface roughness, $R_{a}$ in this region has changed from $\sim 400$ $\mathrm{nm}$ to $\sim 1.5 \mu \mathrm{m}$.

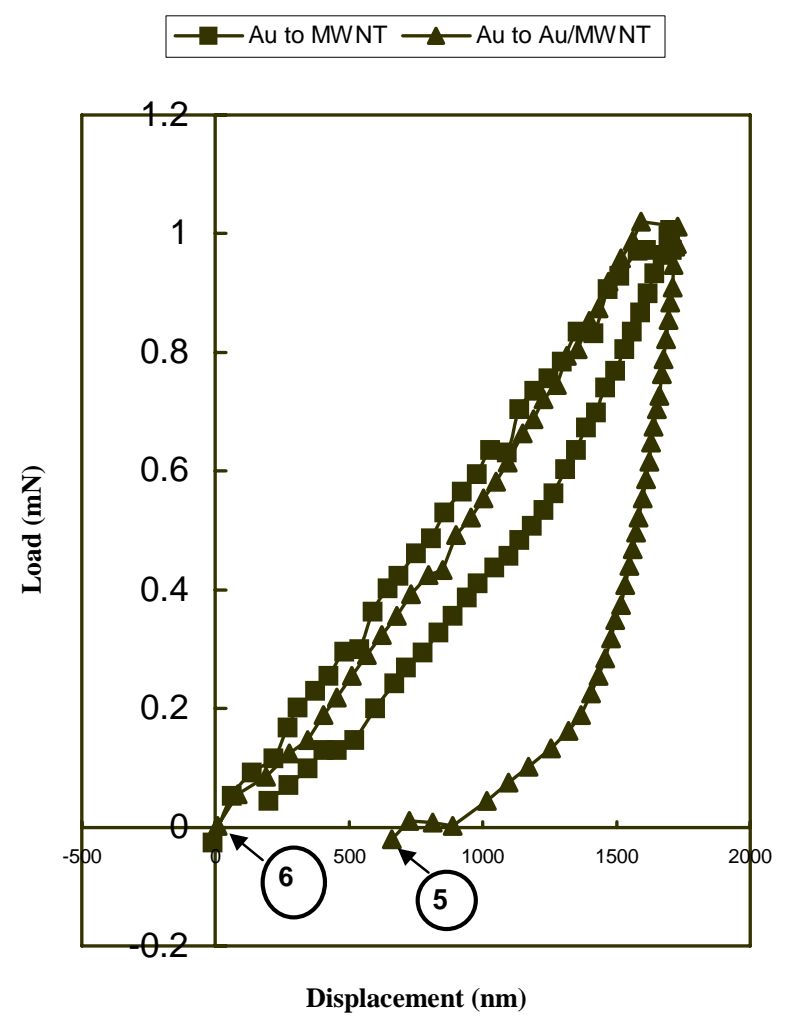

Figure 17: Graph of "load vs. depth" for Au-MWNT

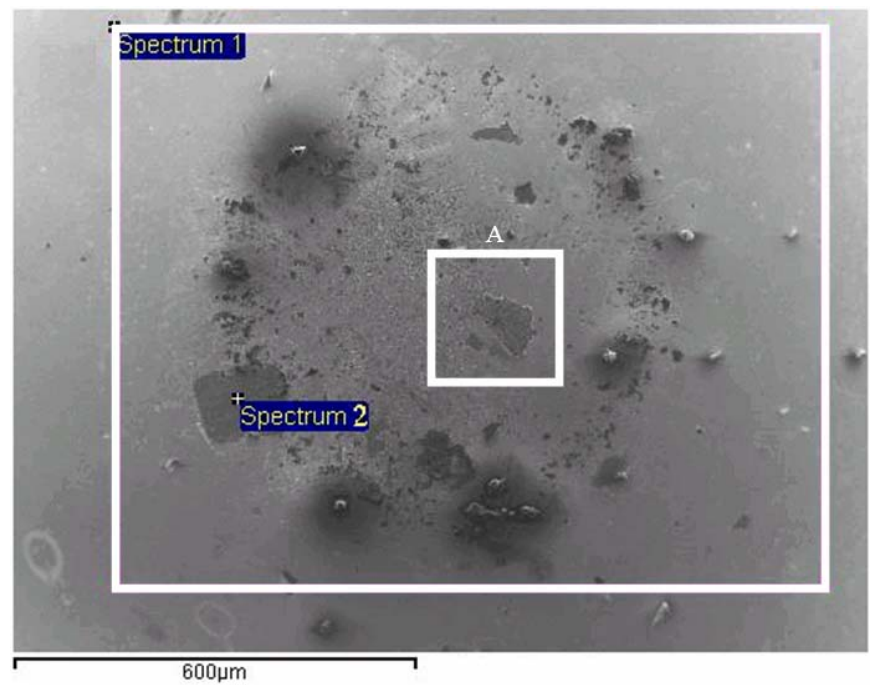

Figure 18: Au micro-contact after contact with Au/MWNT substrate. 

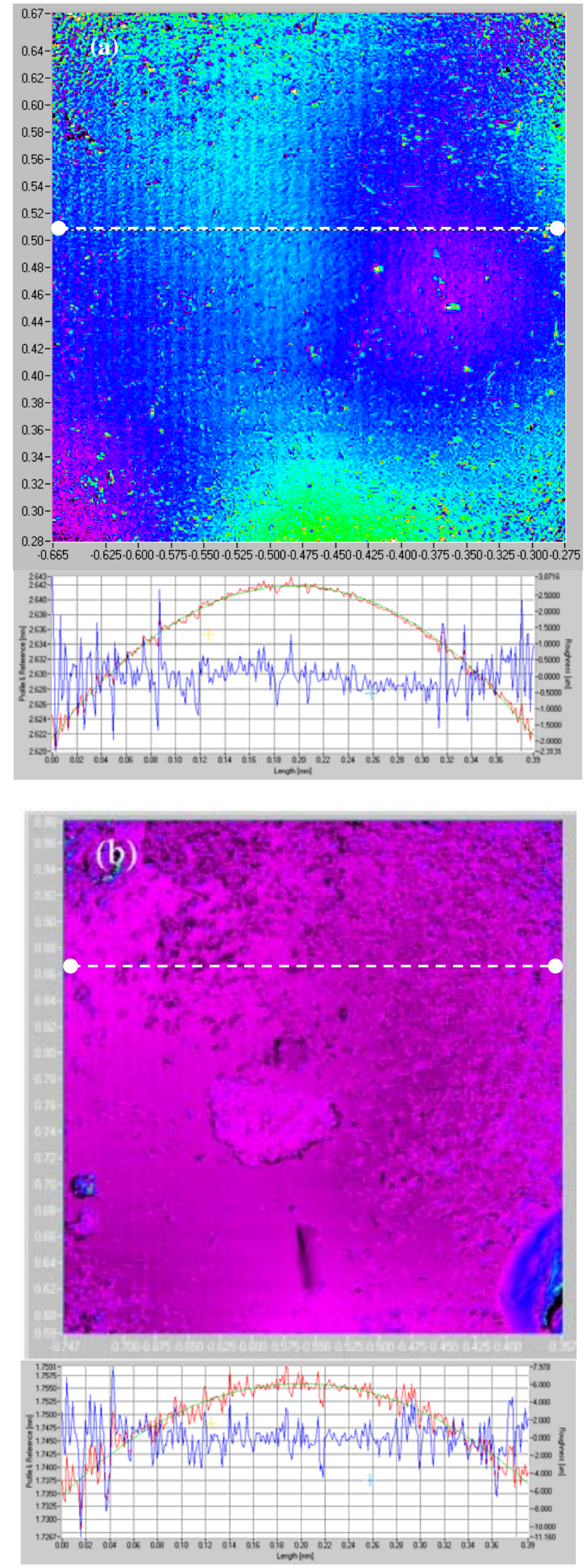

Figure 19: (a) Fresh and (b) Tested Au (ball) micro-contact with sphere removed, $301 \times 301(400 \mu \mathrm{m} \times 400 \mu \mathrm{m})$ using TaiCaan (Xyris 4000CL).

Fig 18 shows the area analysed by X-ray spectroscopy on the Au (ball) micro-contact "Spectrum
1". Fig 20 shows an EDX spectrum for the surface. Au is the predominantly observed with ' $\mathrm{C}$ ' and ' $\mathrm{O}$ ' also observed. This is consistent with the composition of the film, with some additional surface contamination and water adsorbtion. The overall atomic percent of ' $\mathrm{Au}$ ' is $38.60 \%$, ' $\mathrm{C}$ ' is $55.49 \%$ and 'O' $5.91 \%$ for the area "Spectrum 1".

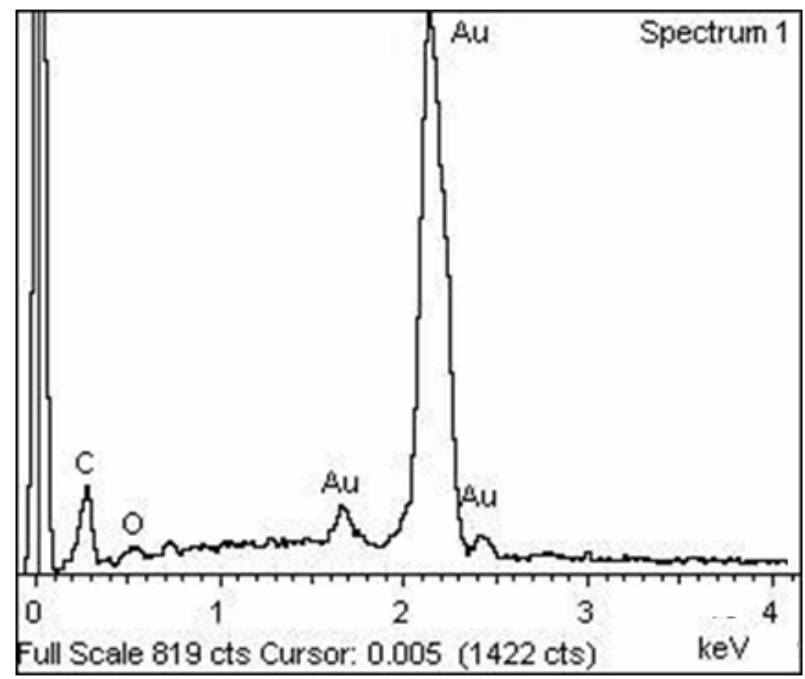

Figure 20: EDX spectrum of Au micro-contact surface.

When a point on the exposed hemisphere $(\mathrm{Au}$ ball contact) was analysed, marked 'Spectrum 2', Fig 18. The 'Fe' peak was predominantly observed and ' $\mathrm{Cr}$ ' peak indicates both element comes from the stainless steel ball, Fig 21. The atomic percent shows ' $\mathrm{Fe}$ ' is $68.69 \%$, ' $\mathrm{Cr}$ ' is $19.08 \%$, ' $\mathrm{C}$ ' is $11.67 \%$ and ' $\mathrm{Au}$ ' is $0.57 \%$ thus indicates that wear has occurred on the Au micro-contact exposing the surface of the ball. No evidence of deformation or change in chemical composition on $\mathrm{Au} / \mathrm{MWNT}$ surfaces can be detected.

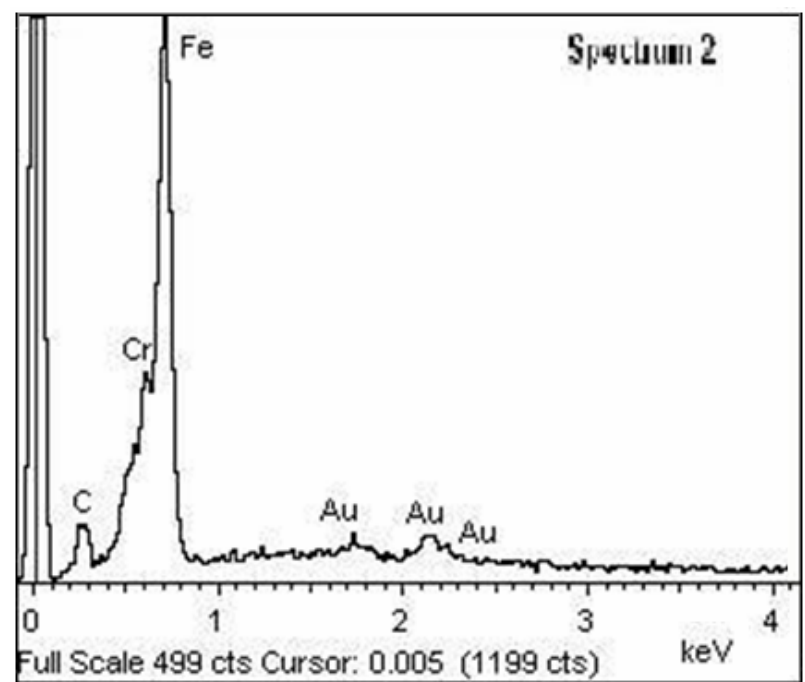

Figure 21: EDX spectrum of exposed hemisphere on the Au microcontact surface.

Even though the Au-Au/MWNT contact pair shows improvement to the contact resistance, further development is needed, to avoid adhesion between the contact pair, which could degrade the contact resistance during extended load 
cycles. This phenomenon is clearly seen in Fig 6 where during unloading there is still contact resistance measured until total separation of the contact pair. Moreover, creep can be seen in Fig 16 (curve at region 2) this is identified as the mechanism responsible for the increase in stiction [16].

\section{IIV. CONCLUSION.}

The applied force (at low contact force) and contact resistance between $\mathrm{Au}-\mathrm{Au} / \mathrm{MWNT}$ composite contact pairs was investigated using a modified nanoindentation apparatus and 4-wire measurement methods. This contact pair combination is compared to the $\mathrm{Au}-$ MWNT pair and the contact resistance is reduced. The performance is comparable to a $\mathrm{Au}-\mathrm{Au}$ contact pair also studied as a benchmark for the new material. Furthermore during ten load cycles of $\mathrm{Au}-\mathrm{Au} / \mathrm{MWNT}$ contact pair shows stable and constant contact resistance.

The study of contact resistance modelling based on existing analytical models shows that there is a discrepancy with the benchmark Au-Au surface. This leads to the conclusion that the mechanics of such surfaces at low force must fall outside the current understanding. An initial study based on FEA shows that conduction through the thin film conductor leads to an increase in the predicted resistance, but that further modifications are required.

This experimental method is applicable to MEMS relay micro-contacts and will serve as a platform for our future research and investigation of $\mathrm{Au} / \mathrm{MWNT}$ $\mathrm{Au} / \mathrm{MWNT}$ and $\mathrm{Au} / \mathrm{SWNT}-\mathrm{Au} / \mathrm{SWNT}$ contact pairs with different quality and length of CNT and thickness of Au on the carbon nanotubes.

\section{Acknowledgements}

The authors would like to thank Dr. S.Abu-Sharkh of the School of Engineering Sciences for his contribution to the FEA study, and to Dr D.Smith of the School of Physics and Astronomy, for providing the facilities for developing the MWNT surfaces.

\section{References}

[1] Coutu, R. A., Kladitis, P. E., Leedy, K. D. and Crane, R. L., 2004, "Selecting Metal Alloy Electric Contact Materials for MEMS Switches," Journal of Micromechanics and Microengineering, (14) pp. 1157-1164.

[2] Gao, D., Wijesundara, M. B. J., Carraro, C., Low, C. W., Howe, R. T. and Maboudian, R., 2003, "High Modulus Polycrystalline 3C-SiC Technology for RF MEMS," The 12th International Conference on Solid State Sensors, Actuators and Mircosystems, 3D3.4, pp. 1160-1163.

[3] Lian, G. D., Dickey, E. C., Ueno, M. and Sunkara, M. K., 2002, "Ru-doped Nanostructured Carbon Films," Diamond and Related Materials, 11, pp. 1890-1896.

[4] Yaglioglu, O., Hart, A. J., Martens, R. and Slocum, A. H., 2006, "Method of characterizing electrical contact properties of carbon nanotube coated surfaces," Review of Scientific Instruments, 77, pp 095105/1-3.
[5] Yu, M. F., Lourie, O., Dyer, M. J., Moloni, K., Kelly, T. F. and Ruoff, R.S., 2000, "Strength and Breaking Mechanism of Multiwalled Carbon Nanotubes Under Tensile Load," Science, 287(5453), pp. $637-640$.

[6] Wong EW, Sheehan PE, Lieber CM, 1997 "Nanobeam Mechanics: Elasticity, Strength, and Toughness of Nanorods and Nanotubes," Science, 277, pp. 1971-5.

[7] Qi, H.J., Teo, K.B.K., Lau, K.K.S., Boyce, M.C., Milne, W.I., Robertson, J. and Gleason, K.K., 2003, "Determination of Mechanical Properties of Carbon Nanotubes and Vertically Aligned Carbon Nanotube forests using Nanoindentation," Journal of Mechanics and Physics of Solids, 51, pp. 2213-2237.

[8] Thostenson, E. T., Ren, Z. and Chou, T.W., 2001, "Advances in the Science and Technology of Carbon Nanotubes and their Composites: A review," Composites Science and Technology, 61, pp. 1899-1912.

[9] Hjortstam, O., Isberg, P., Söderholm, S. and Dai, H., 2004, “Can we achieve ultra-low resistivity in carbon nanotube-based metal composites?" Journal of Applied Physics A, Materials Science \& Processing, 78, pp. 1175-1179.

[10] Dickrell III, D. J. and Dugger, M. T., 2005, "The effects of surface contamination on resistance degradation of hot-switched low-force MEMS electrical contacts," Electrical Contacts, Proceedings of the Annual Holm Conference on Electrical Contacts, v 2005, Electrical Contacts 2005 - Proceedings of the Fifty-First IEEE Holm Conference on Electrical Contacts, pp. 255-258.

[11] McBride, J. W. 2006, "The Loaded Surface Profile: A new technique for the investigation of contact sirfaces," ICEC2006, pp. 150-156.

[12] Coutu, R.A., Jr., Reid, J.R., Cortez, R., Strawser, R.E., and Kladitis, P.E., 2006, "Microswitches with sputtered Au, AuPd,Auon-AuPt, and AuPtCu alloy electric contacts," IEEE Transactions on Components and Packaging Technologies, v 29, n 2, pp. 341-9.

[13] Chang. W., 1997, "An elastic-plastic model for a rough surface with an ion-plated metallic coating," Journal of Wear, Vol.212, pp. 229-237.

[14] Chang, W.R., Etsion, I. and Bogy, D.B., 1987, "An elasticplastic model for the contact of rough surfaces," Transactions of the ASME. Journal of Tribology, v 109, n 2, pp. 257-63.

[15] Mikrajuddin, A., Shi, F.G., Kim, H.K. and Okuyama, K., 1999, "Size-dependent electrical constriction resistance for contacts of arbitrary size: from Sharvin to Holm limits," Materials Science in Semiconductor Processing, v 2, n 4, pp. 321-7.

[16] Gregori, G. and Clarke, D. R., 2006, "The interrelation between adhesion, contact creep, and roughness on the life of gold contacts in radio-frequency microswitches," Journal of Applied Physics, 100, pp. 094904-1/10. 